

\section{LORD EVANS}

Lord Evans, physician to the London Hospital, died on October 26, 1963 at the age of $60 . \mathrm{He}$ attained eminence as a consultant in general medicine and his services in this field were greatly sought and readily given. He had been physician in turn to Queen Mary, King George VI, Queen Elizabeth the Queen Mother, and for the past ten years to Queen Elizabeth II.

The care which he devoted to the sick at his hospital in the East End of London was no less than that which he gave to one residing in a royal palace, because he wore the cloth of a true doctor who liked doctoring for its own sake and without thought of his patient's social status. He dispensed comfort liberally and effortlessly, for his dignified bearing and unstinted kindness were his natural virtues during his unhurried visits at the bedside. He was blessed with a rich low-toned voice which helped him as he instilled hope and confidence in those stricken by illness, and who in turn became aware that he stood by their sides in their fight to regain health.

He showed rare skill and shrewdness in the art of clinical diagnosis which usually concluded without recourse to extravagant laboratory tests, for he respected his patient's account of his illness and was alert to uncover physical signs which the unwary might fail to discover. In the management and treatment of the illness he drew freely from his rich fund of common sense and he never neglected the man for his disease. His cautious judgment never allowed his hand to move in prescriptionwriting in front of his discerning mind which first considered the need and the proven efficacy of the medicine he might use; thus, he prescribed placebos as often as active drugs, knowing them to have equal power in many instances to sustain patience while Nature was given time to heal. At a time of crisis he would remain imperturbable and would not abandon his customary equanimity. Not given to despondency himself, he dispelled gloom from patients who might be prone to it, and whom he would cajole to adopt his own optimistic mood. Little wonder that one so capable of bringing comfort and calm into the sick-room was in such great demand by family doctors who sought his aid in the management of patients and their relatives.

His work on nephritis, carried out in collaboration with his colleagues at the London Hospital, increased his interest in systemic hypertension, and it was in these two subjects within the field of general medicine that he had special knowledge. His consulting practice expanded widely, and this suited his disinclination to undertake research work which would hinder his zeal in looking after patients, a function more to his liking and one in which he was to show so much proficiency.

When the British Heart Foundation came into being under the patronage of the Duke of Edinburgh, and with Lord Alexander of Tunis as its president, the Royal College of Physicians was invited to nominate a representative to serve on the Founding Committee; it elected Lord Evans. Later, when he was appointed joint Vice-Chairman of the Foundation's Appeal Committee he took up his duties with enthusiasm, and proceeded to recruit the captains of industry and of commerce to help raise monies to support research work into the cause and treatment of heart disease. It is freely acknowledged that the initial success of the appeal could not have been won without the earnest efforts he expended on its behalf. In recognition of this very material help to cardiology the British Cardiac Society invited him to become its member, and it gave him pleasure to accept the invitation.

When his younger daughter met her death in tragic circumstances, and again when his wife became seriously indisposed, he kept his grief to himself. A year ago when he himself was visited by an incurable illness, which imposed on him poignant suffering, he continued to preserve the same calm serenity which his friends had always identified with him, but who now marvelled at his ability to maintain his habitual poise in the face of such cruel odds. Our admiration of his unyielding courage grew as we watched him wane physically.

His untimely passing has left a void in the ranks of consulting medicine which the profession will find difficult to fill.

WILLIAM EVANS 